\title{
Biological false positive serological tests for syphilis among drug addicts
}

\author{
RICHARD E. KAUFMAN, SUZANNE WEISS, JAMES D. MOORE, VIRGINIA \\ FALCONE, AND PAUL J. WIESNER \\ From the Center for Disease Control, Atlanta, Georgia, and the National Institute of Mental Health Clinical \\ Research Center, Lexington, Kentucky
}

A high frequency of biological false positive (BFP) serological tests for syphilis among drug addicts was initially reported in 1961 (Boak, Carpenter, and Miller, 1961). Several subsequent studies (Harris, Brown, Portnoy, and Price, 1962; Harris and Andrei, 1967; Tuffanelli, 1968; Cherubin and Millian, 1968) have noted a widely varying prevalence of this phenomenon. The purpose of the present paper is to examine the prevalence of BFP reactions in a large group of drug addicts and to compare it with that of such reactions in the general population. In addition, an evaluation of variations in the incidence of BFP reactions is undertaken, as they relate to types of serological tests performed and to clinical factors that contribute to the BFP reaction.

\section{Subjects and methods}

Two groups were studied. The first comprised 1,646 drug addicts consecutively admitted to the National Institute of Mental Health Clinical Research Center at Lexington, Kentucky. Sera from all were tested with a VDRL slide test and if reactive or weakly reactive further tested by the fluorescent treponemal antibody absorption (FTA-ABS) method (Hunter, Deacon, and Meyer, 1964). The second group, composed of 197 consecutively admitted drug addicts, was screened with four reagin tests-VDRL, rapid plasma reagin card (RPR), unheated serum reagin (USR), and automated reagin test (ART), and three treponemal tests-FTA-ABS, automated FTA-ABS (AFTA), and microhaemagglutination TrepoReceived for publication December 10, 1973

Address for reprints: Center for Disease Control, Bureau of State Services Technical Information Services, Atlanta, Georgia 30333, USA nema pallidum (MHA-TP) (Uete, Fukazawa, Ogi, and Takeuchi, 1971). In addition, this second group was assessed for clinical and drug use factors that might contribute to a BFP reaction, and the sera tested for hepatitis B antigen by counterelectrophoresis.

The demographic particulars of each population were essentially similar. Ages ranged from 16 to 72 years, the mean being 25 . Of the total sample, 54 per cent. were black, 42 per cent. white, and 4 per cent. mainly SpanishAmerican. Eighty per cent. of both samples were men. The vast majority of patients were from urban centres east of the Mississippi River. Nearly all used intravenous heroin.

\section{Results}

In the group of 1,646 sera, 244 (14.8 per cent.) were reactive or weakly reactive by the VDRL test (Table I). Of these, $143(58.6$ per cent.) had nonreactive FTA-ABS tests and were considered to be BFP reactors. Female addicts showed a greater frequency of reactive VDRL tests than men. Similarly, women had a greater number of reactive FTA-ABS tests, and thus a greater prevalence of syphilis. Conversely, men with a reactive VDRL test were less likely to have a reactive FTA-ABS test, and hence had a greater prevalence of BFP reactions. However, the overall prevalence of $B F P$ reactions among all specimens examined showed little difference between male and female drug addicts.

Table II summarizes the results in the second group. Twelve ( 6.1 per cent.) of the 197 sera were reactive in one or more reagin tests, and nonreactive in all treponemal tests, thus satisfying the criteria for a

TABLE I Results of serological tests performed on 1,646 narcotic addicts on first admission to the NIMH Clinical Research Centre

\begin{tabular}{|c|c|c|c|c|c|c|c|c|c|}
\hline \multirow{3}{*}{ Sex } & \multirow{3}{*}{$\begin{array}{l}\text { No. of } \\
\text { specimens } \\
\text { examined }\end{array}$} & & & \multicolumn{3}{|c|}{ Reactive FTA-ABS tests } & \multicolumn{3}{|c|}{$\begin{array}{l}\text { Nonreactive } F T A-A B S \text { tests } \\
\text { (Biological false-positive reactors) }\end{array}$} \\
\hline & & \multicolumn{2}{|c|}{ Reactive VDRL tests } & \multirow{2}{*}{ No. } & \multirow{2}{*}{$\begin{array}{l}\text { Per cent. } \\
\text { of reactive } \\
\text { VDRL tests }\end{array}$} & \multirow{2}{*}{$\begin{array}{l}\text { Per cent of } \\
\text { all specimens } \\
\text { examined }\end{array}$} & \multirow{2}{*}{ No. } & \multirow{2}{*}{$\begin{array}{l}\text { Per cent. } \\
\text { of reactive } \\
\text { VDRL tests }\end{array}$} & \multirow{2}{*}{$\begin{array}{l}\text { Per cent. } \\
\text { of all } \\
\text { examined }\end{array}$} \\
\hline & & No. & Per cent. & & & & & & \\
\hline $\begin{array}{l}\text { Male } \\
\text { Female }\end{array}$ & $\begin{array}{r}1,320 \\
326\end{array}$ & $\begin{array}{r}180 \\
64\end{array}$ & $\begin{array}{l}13 \cdot 6 \\
19 \cdot 6\end{array}$ & $\begin{array}{l}64 \\
37\end{array}$ & $\begin{array}{l}35 \cdot 3 \\
57 \cdot 8\end{array}$ & $\begin{array}{r}4 \cdot 8 \\
11 \cdot 3\end{array}$ & $\begin{array}{r}116 \\
27\end{array}$ & $\begin{array}{l}64 \cdot 7 \\
42 \cdot 2\end{array}$ & $\begin{array}{l}8 \cdot 8 \\
8 \cdot 3\end{array}$ \\
\hline Total & 1,646 & 244 & $14 \cdot 8$ & 101 & $41 \cdot 4$ & $6 \cdot 1$ & 143 & $58 \cdot 6$ & $8 \cdot 7$ \\
\hline
\end{tabular}


BFP reaction. Eight $(4 \cdot 1$ per cent.) sera were not reactive in the reagin tests, but were reactive in one of the three treponemal tests. We have tentatively termed such reactivity patterns 'treponemal false positives'. Of the fifteen remaining active sera, nine were clearly syphilitic on the basis of the serological

TABLE II Reactivity in sera from narcotic addicts: reagin and treponemal tests for syphilis

\begin{tabular}{|c|c|c|}
\hline Type of reactivity & $\begin{array}{l}\text { Number of } \\
\text { patients }\end{array}$ & $\begin{array}{l}\text { Percentage of } \\
\text { total }\end{array}$ \\
\hline No reactive test & 162 & $81 \cdot 7$ \\
\hline $\begin{array}{l}\text { Only reagin test reactive (BFP) } \\
\text { Reactive in one treponemal test only }\end{array}$ & 12 & $6 \cdot 1$ \\
\hline$(\mathrm{TFP})$ & 8 & $4 \cdot 1$ \\
\hline $\begin{array}{l}\text { Reactive in both reagin and treponemal } \\
\text { tests }\end{array}$ & 15 & $7 \cdot 6$ \\
\hline A. Syphilitic & 9 & $4 \cdot 6$ \\
\hline B. Uncertain diagnosis & 6 & $3 \cdot 0$ \\
\hline
\end{tabular}

test results. Six, however, reacted in such atypical fashion as to elude diagnostic categorization.

The serological patterns of each of these subgroups are presented in Tables III to VI.

Among the twelve BFP reactors (Table III) only two had nonreactive VDRL tests. These same two were the only sera reactive in but one reagin test, the $\mathrm{RPR}$ card. In contrast, one-half of the group were reactive in all four reagin tests.

TABLE II I Serological reactivity in twelve biological false positive reactors (All treponemal tests nonreactive)

\begin{tabular}{|c|c|c|c|c|}
\hline Patient no. & $V D R L^{\mathrm{a}}$ & $R P R^{\mathrm{a}}$ & $A R T^{\mathrm{a}}$ & $U S R^{\mathrm{a}}$ \\
\hline 1 & NR & $1: 1$ & NR & NR \\
\hline 2 & NR & $1: 2$ & NR & NR \\
\hline 3 & WR & $1: 2$ & $1: 4$ & $\mathbf{R}$ \\
\hline 4 & WR & $1: 1$ & $1: 1$ & $\mathbf{R}$ \\
\hline 5 & WR & NR & NR & WR \\
\hline 6 & WR & NR & $1: 1$ & NR \\
\hline 7 & $1: 2$ & NR & NR & WR \\
\hline 8 & $1: 8$ & $1: 2$ & $1: 4$ & $\mathrm{R}$ \\
\hline 9 & $1: 4$ & $1: 1$ & $1: 2$ & $\mathbf{R}$ \\
\hline 10 & $1: 32$ & $1: 8$ & $1: 32$ & $\mathbf{R}$ \\
\hline 11 & $1: 2$ & $1: 2$ & $1: 4$ & $\mathbf{R}$ \\
\hline 12 & $1: 1$ & NR & $1: 1$ & NR \\
\hline
\end{tabular}

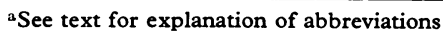

$\mathrm{NR}=$ Nonreactive $\quad \mathrm{WR}=$ Weakly reactive $\quad \mathrm{R}=$ Reactive

Numbers indicate dilutions in titred tests

The eight 'treponemal false positive' reactors (Table IV) with serological reactivity in only one of the three treponemal tests performed are the laboratory antithesis of the BFP. Of the addicts who were syphilitic on the basis of their serological test results (Table V), all demonstrated reactivity in the FTAABS and MHA-TP tests. The AFTA did not support the diagnosis in three patients. Table VI demonstrates the serological pattern in six specimens that could not be readily placed in any diagnostic category. All demonstrated reactivity in varying combinations of treponemal and nontreponemal tests.

TABLE IV Serological reactivity in eight 'treponemal false positive' reactors (TFP)

\begin{tabular}{|c|c|c|c|}
\hline Patient no. & $F T A-A B S^{\mathrm{a}}$ & $A F T A^{\mathrm{a}}$ & $M H A-T P^{\mathrm{a}}$ \\
\hline 1 & NR & $\mathbf{R}$ & NR \\
\hline 2 & NR & NR & $1: 80$ \\
\hline 3 & NR & NR & $1: 80$ \\
\hline 4 & NR & NR & $1: 80$ \\
\hline 5 & B & NR & NR \\
\hline 6 & B & NR & NR \\
\hline 7 & B & NR & NR \\
\hline 8 & $\mathbf{B}$ & NR & NR \\
\hline
\end{tabular}

aSee text for explanation of abbreviations

$\mathrm{NR}=$ Nonreactive $\quad \mathrm{B}=$ Borderline $\quad \mathrm{R}=$ Reactive

Numbers indicate dilutions in titred tests

TABLE $\mathrm{v}$ Serological reactivity th nine syphilitic addicts

\begin{tabular}{|c|c|c|c|c|c|c|c|}
\hline Patient no. & $V D R L^{\mathrm{a}}$ & $R P R^{\mathrm{a}}$ & $A R T^{\mathrm{a}}$ & $U S R^{\mathrm{a}}$ & $F T A^{\mathrm{a}}$ & $A F T A^{\mathrm{a}}$ & $M H A-T P^{\mathrm{a}}$ \\
\hline 1 & $1: 1$ & $1: 2$ & $1: 2$ & $\mathbf{R}$ & $\mathbf{R}$ & $\mathbf{R}$ & $1: 80$ \\
\hline 2 & $1: 2$ & $1: 4$ & $1: 8$ & $\mathbf{R}$ & $\mathbf{R}$ & $\mathbf{R}$ & $1: 10240$ \\
\hline 3 & $1: 1$ & $1: 2$ & $1: 2$ & $\mathbf{R}$ & $\mathbf{R}$ & $\mathbf{R}$ & $1: 1280$ \\
\hline 4 & NR & NR & NR & NR & B & $\mathrm{R}$ & $1: 1280$ \\
\hline 5 & NR & NR & NR & NR & $\mathbf{R}$ & $\mathbf{R}$ & $1: 80$ \\
\hline 6 & NR & NR & NR & NR & $\mathbf{R}$ & NR & $1: 160$ \\
\hline 7 & NR & NR & NR & NR & $\mathbf{R}$ & NR & $1: 1280$ \\
\hline 8 & NR & NR & NR & NR & $\mathbf{R}$ & NR & $1: 1280$ \\
\hline 9 & NR & $1: 4$ & NR & NR & B & $\mathbf{R}$ & $1: 160$ \\
\hline
\end{tabular}

aSee text for explanation of abbreviations

$\mathrm{NR}=$ Nonreactive $\quad \mathrm{B}=$ Borderline $\quad \mathrm{R}=$ Reactive

Numbers indicate dilutions in titred tests

TABLE VI Serological reactivity in six addicts with uncertain diagnosis

\begin{tabular}{|c|c|c|c|c|c|c|c|}
\hline Patient no. & $V D R L^{\mathrm{a}}$ & $R P R^{\mathrm{a}}$ & $A R T^{\mathrm{a}}$ & $U S R^{\mathrm{a}}$ & $F T A^{\mathrm{a}}$ & $A F T A^{\mathrm{a}}$ & $M H A-T P a$ \\
\hline 1 & W & NR & NR & NR & B & NR & NR \\
\hline 2 & $1: 1$ & NR & NR & NR & B & NR & NR \\
\hline 3 & $1: 4$ & $1: 4$ & $1: 8$ & $\mathbf{R}$ & B & NR & NR \\
\hline 4 & $1: 4$ & $1: 4$ & $1: 16$ & $\mathbf{R}$ & NR & $\mathbf{R}$ & NR \\
\hline 5 & W & NR & NR & W & NR & $\mathbf{R}$ & NR \\
\hline 6 & $1: 4$ & NR & $1: 2$ & $\mathbf{R}$ & NR & NR & $1: 80$ \\
\hline
\end{tabular}

aSee text for explanation of abbreviations

$\mathrm{NR}=$ Nonreactive $\quad \mathrm{B}=$ Borderline $\quad \mathrm{R}=$ Reactive

$\mathrm{W}=\mathrm{W}$ eakly reactive

Numbers indicate dilutions in titred tests

No significant correlations were evident between the serological reaction pattern and the duration of heroin use or the proximity of specimen sampling to heroin use. All 197 sera were tested for the presence of hepatitis B antigen. Of nine positive sera, only one was a BFP reactor. Similarly a history or present evidence of serum hepatitis or of gonorrhoea did not show any correlation. As expected a history of syphilis was found more often among those with serologically confirmed syphilis. 


\section{Comment}

A BFP reaction is generally considered the combination of a reactive reagin, or nontreponemal, test and a nonreactive treponemal test. In our initial survey of 1,646 addicts, the VDRL and FTA-ABS tests were employed since they are the most commonly used reagin and treponemal tests. In addition, the FTAABS test has been shown to be more sensitive and nearly as specific as what some consider the nonpareil of syphilis serology, the Treponema pallidum immobilization (TPI) test (Wuepper, Bodily, and Tuffanelli, 1966). That this degree of sensitivity and specificity is the case among drug addicts has been shown in studies comparing both the FTA test (Harris and others, 1962) and the FTA-ABS test (Tuffanelli, 1968) with the TPI test.

There are two levels of prevalence reported here. The first is the frequency of BFP phenomena among reactive VDRL tests. It answers the following question: given a reactive VDRL test in a drug addict what is the likelihood of it representing a syphilitic or a BFP reaction? The second level addresses itself to the frequency of BFP reactions among all specimens examined and, hence, to whether there is a greater incidence among drug addicts than in the general population.

The four initial reports (Boak and others, 1961; (Harris and others, 1962; Harris and Andrei, 1967; Tuffanelli, 1968) of BFP reactivity in addicts dealt with its prevalence among reactive VDRL tests. Results ranged from 33.3 to 94.8 per cent. This wide variation reflects, to some extent, differences in patient selection. Our overall figure is in a consecutive group which did not exclude patients with a history of syphilis or the presence of disease. It correlates well with the study of Harris and others (1962) in which, if we combine those patients with and without histories of syphilis, the prevalence is 65.4 per cent. The 58 per cent. prevalence among female addicts reported by Harris and Andrei (1967) is identical to our overall figure, but higher than the $42 \cdot 2$ per cent. we found in our female population. This discrepancy is related to the fact that the prevalence of syphilis among our female addicts was considerably higher than in men-a statistic that runs counter to that reported in the general population where the reverse is true. This marked increase in syphilis may result, in part, from the prostitution frequently engaged in by female addicts to support their addiction.

The lowest prevalence reported (Tuffanelli, 1968) is 33 per cent., but this is in a group of former addicts who had not taken drugs for a year or more at the time of the study. The initial report, by Boak and others (1961), of a dramatically high prevalence of
94.8 per cent. remains unreproduced, and we cannot explain that result.

The second form of prevalence is the frequency of BFP reactions among all the sera examined. Our figures of 8.8 per cent. in men and 8.3 per cent. in women are consistent with those of Cherubin and Millian (1968) who reported an overall prevalence of 8 to 13 per cent. in men and 5 to 6 per cent. in women, varying according to age. In several recent surveys (U.S. Department of Health, Education and Welfare, 1972; Wong, 1969; Garner, 1970; Johannsson, 1970; Johannsson and Lassus, 1970) of BFP reactions in relatively unselected populations, the prevalence was uniformly less than 1 per cent., indicating a far lower rate than that found among drug addicts.

In the second group of 197 sera, the overall prevalence of BFP reactions was $6 \cdot 1$ per cent., consistent with the larger series. Twenty-seven sera demonstrated reactivity in at least one of the four reagin tests performed. Twelve of these $(44.5 \mathrm{per}$ cent.) were BFP reactions-a prevalence comparable with the 58.6 per cent. found in the larger sample in which only the VDRL and FTA-ABS tests were used. These figures emphasize that reagin reactivity in seras from drug addicts must be corroborated by treponemal testing before making a diagnosis of syphilis.

Problematic in this regard, however, is our finding of eight so-called 'false positive treponemal' reactors. This has been reported in FTA-ABS testing (Evans, Casals, Opton, Borman, Levine, and Cuadrado, 1971), particularly among patients with immunological disorders (Goldman and Lantz, 1971), but we are unaware of any report of such phenomena among drug addicts. Thus, pending more complete data, a questionable FTA-ABS test in a drug abuser may have to be confirmed by other treponemal tests together with the clinical and epidemiological findings. The AFTA showed fewest false positive reactions among the three treponemal tests, though the one instance occurred in a serum which was negative in both the FTA-ABS and MHA-TP tests. Among patients with clear-cut syphilis, the AFTA proved the least sensitive treponemal test. With the small numbers in this series, however, one cannot draw reliable conclusions regarding the comparable sensitivity and specificity of these tests.

Diagnostic difficulties arose in six patients whose sera reacted in seemingly capricious fashion. In several cases an argument for a serological diagnosis of syphilis might be made, but in no case was this clear. Such atypically reactive sera warrant further investigation.

There were no significant correlations between a past history of syphilis and either BFP or TFP 
reactivity. As would be expected, however, a history of syphilis was obtained in a significantly higher number of patients whose sera demonstrated syphilitic reactivity. Those in the uncertain category also included three persons with a questionable history of syphilis, suggesting that some may actually have had syphilis. A history of gonorrhoea bore no relationship to serological activity.

The reason for the BFP reactions in drug addicts remains elusive. Immunological studies by Tuffanelli, Wuepper, Bradford, and Wood (1967) and Tuffanelli (1968) did not reveal any significant correlations. In both of our groups there were no clinical differences between the BFP and TPF reactors, and those with no serological reactivity. An association between serum hepatitis and BFP reactions has been suggested, but our study did not bear this out. Neither the presence of hepatitis B antigen nor a previous history of hepatitis correlated with an increased incidence of BFP reactions.

In terms of the factors surrounding drug use, we could find no suggestive aetiological associations. Although the vast majority of patients in this study were intravenous heroin users, there were no differences between the BFP reactors and the nonreactors. Similarly, the duration of heroin abuse, or the proximity of serum sampling to the most recent heroin injection appeared to be unrelated to serological reactivity.

In conclusion, BFP reactions are found at least ten times more frequently among drug addicts than in the general population. They seem to be related to active drug abuse and may disappear with extended abstinence; this awaits a longitudinal study. Aetiological explanations centring in an association with hepatitis B infection are not supported by our findings. Whatever the cause, reactive reagin tests in drug addicts should always be confirmed by treponemal tests, and conversely, treponemal tests should be performed only in conjunction with reagin tests. In view of possible borderline TFP reactions, further study of treponemal test specificity in drug addicts is certainly warranted and such studies should include the TPI test.

\section{Summary}

Sera from 1,646 drug abusers were screened for biological false positive reactivity. Using the VDRL and FTA-ABS tests, the prevalence was 8.7 per cent., approximately ten times greater than that in the general population. A second group of sera from 197 addicts screened with four reagin tests and three treponemal tests, showed a $6 \cdot 1$ per cent. prevalence of BFP reactions. In addition, this group had 'treponemal false positive' reactions, and patterns of serological reactivity that could not be readily categorized. Hence, reagin tests in drug abusers should be confirmed by treponemal tests, and treponemal tests should be performed only in conjunction with reagin tests. No significant associations could be found between BFP reactions and particular aspects of drug use, liver disease, or gonorrhoea.

\section{References}

Boak, R. A., Carpenter, C. M., and Miller, J. N. (1961) f. Amer. med. Ass., 175, 326

Cherubin, C., and Millian, S. J. (1968) Ann. intern. Med., 69, 739

Evans, A. S., Casals, J., Opton, E. M., Borman, E. K., Levine, L., and Cuadrado, R. (1971) Amer. F. Epidemiol., 93, 111

GARNER, M. F. (1970) f. clin. Path., 23, 31

Goldman, J. N., and LANTZ, M. A. (1971) f. Amer. med. Ass., 217, 53

Harris, A., Brown, L., Portnoy, J., and Price, E. V. (1962) Publ. Hlth Rep. (Wash.), 77, 537

HARRIS, W.D.M., and ANDREI, J. (1967) N. Y. St.f. Med., 67, 2967

Hunter, E. F., Deacon, W. E., and MeYer, P. E. (1964) Publ. Hlth Rep. (Wash.), 79, 410

Johannsson, E. A. (1970) Acta derm.-venereol. (Stockh)., 50, 305

- and Lassus, A. (1970) Ann. clin. Res., 2, 32

Tuffanelli, D. L. (1968) Acta derm.-venereol. (Stockh.), 48, 542

-, Wuepper, K. D., Bradford, L. L., and Wood, R. M. (1967) New Engl. F. Med., 276, 258

Uete, T., Fukazawa, S., OgI, K., and Takeuchi, Y. (1971) Brit. F. vener. Dis., 47, 73

U.S. Dept. Health, Education, and Welfare (1972) $V D$ Fact Sheet. Publ. No. (HSM) 73-8195

Wong, K. O. (1969) Brit. F. Derm., 81, 186

Wuepper, K. D., Bodily, H. L., and Tuffanelli, D. L. (1966) Arch. Derm., 94, 152

Epreuves sérologiques, biologiquement faussement positives pour la syphilis chez les drogués

Les sérums de 1.646 drogués furent examinés vis-à-vis de leur réactivité biologiquement faussement positive (BFP). Avec le VDRL et le FTA-ABS, la prévalence fut de 8,7 pour cent, à-peu-près dix fois plus que pour la population générale. Un deuxième groupe de sérums, provenant de 197 adonnés aux drogues, étudiés sur quatre épreuves réaginiques et sur trois tests tréponémiques, montra une prévalence de 6,1 pour cent de réactions BFP. En plus, ce groupe présentait des réactions 'tréponémiques faussement positives' et le type de réactivité sérologique ne put pas, pour l'instant, être déterminé. A l'avenir, les épreuves réaginiques chez les drogués doivent être confirmées par les tests tréponémiques et ces derniers doivent être effectués seulement en conjonction avec les tests réaginiques. Aucune association significative ne put être trouvée entre les réactions BFP et des aspects particuliers de la drogue employée, d'une maladie hépatique ou de la gonococcie. 